\title{
Distribution of virulence-associated genes and antimicrobial susceptibility in clinical Acinetobacter baumannii isolates
}

\author{
Chao Liu' ${ }^{1, *}$, Yaowen Chang ${ }^{1, *}$, Ying $X u^{2}$, Yun Luo ${ }^{1}$, Linrong $\mathbf{W u}^{1}$, Zhanjun Mei ${ }^{1}$, \\ Shigang $\mathrm{Li}^{1}$, Rui Wang ${ }^{1}$ and $\mathrm{Xu} \mathrm{Jia}^{1}$ \\ ${ }^{1}$ Non-coding RNA and Drug Discovery Key Laboratory of Sichuan Province, Chengdu Medical College, Chengdu, Sichuan, \\ China \\ ${ }^{2}$ Clinical Laboratory, The First Affiliated Hospital of Chengdu Medical College, Chengdu, Sichuan, China \\ *These authors have contributed equally to this work \\ Correspondence to: Rui Wang, email: ruiustb@126.com \\ Xu Jia, email: jiaxu@cmc.edu.cn \\ Keywords: Acinetobacter baumannii; antimicrobial resistance; MDR; virulence genes; PFGE \\ Received: December 11, $2017 \quad$ Accepted: February 26, $2018 \quad$ Published: April 24, 2018 \\ Copyright: Liv et al. This is an open-access article distributed under the terms of the Creative Commons Attribution License 3.0 (CC \\ BY 3.0), which permits unrestricted use, distribution, and reproduction in any medium, provided the original author and source are \\ credited.
}

\section{ABSTRACT}

Acinetobacter baumannii is undoubtedly one of the most clinically significant pathogens. The multidrug resistance and virulence potential of $A$. baumannii are responsible for hospital-acquired nosocomial infections. Unlike numerous investigations on the drug-resistant epidemiology of $A$. baumanni, virulence molecular epidemiology is less studied. Here, we collected 88 A. baumannii clinical isolates, tested their antimicrobial susceptibility to 10 commonly used antibiotics and analyzed the distribution of 9 selected virulence-associated genes, aims to investigate the primary characteristics of the virulence-associated genes that exist in clinically multidrug resistant (MDR) and non-MDR isolates of $A$. baumannii. The MIC results showed the resistance rates of ciprofloxacin $(68.2 \%, 60 / 88)$, gentamicin $(67.0 \%, 59 / 88)$, amikacin $(58.0 \%, 51 / 88)$, tobramycin $(58.0 \%, 51 / 88)$, doxycycline $(67.0 \%, 59 / 88)$, meropenem $(54.5 \%, 48 / 88)$ and imipenem $(65.9 \%, 58 / 88)$ were all above $50 \%$, except for levofloxacin $(34.1 \%, 30 / 88)$, minocycline $(1.1 \%, 1 / 88)$ and polymyxin $\mathrm{B}(0 \%, 0 / 88)$. The Pulsed field gel electrophoresis (PFGE) analysis revealed that the resistance rate of MDR A. baumannii isolates in the Epidemic group was predominant $(79.5 \%, 44 / 58)$, but in the Sporadic group was only $6.7 \%(2 / 30)$. Further investigation on the distribution of virulence genes showed the virulence genes bap (95.5\%), surA1 (92.0\%), BasD (92.0\%), paaE $(88.6 \%)$, pld $(87.5 \%)$, BauA $(62.5 \%)$, omp33-36 (59.1\%) and pgIC (53.4\%) were accounted for high proportion, except for traT ( $0 \%)$. Overall, our results revealed that MDR isolates predominated in the Epidemic A. baumannii isolates, and contained a very high proportion of virulence genes, which may lead to high risk, high pathogenicity and high treatment challenge.

\section{INTRODUCTION}

Acinetobacter spp. were glucose-non-fermentative, non-motile, non-fastidious, catalase-positive, oxidativenegative, and aerobic Gram-negative coccobacilli. Acinetobacter baumannii is the most clinically significant Acinetobacter species associated with hospital-acquired infections worldwide [1]. Although A. baumannii used to be considered as a low virulence pathogen, pneumonia has been the main manifestation of nosocomial infections caused by this pathogen, resulting in a significant impact on the mortality rate of patients [2]. This microorganism has also been identified as the etiological agent responsible for a wide range of other infections, including septicemia, meningitis, and more recently, severe and deadly cases of necrotizing fasciitis [3]. 
A. baumannii was originally recognized as one of the six ESKAPE pathogens (Enterococcus faecium, Staphylococcus aureus, Klebsiella pneumoniae, Acinetobacter baumannii, Pseudomonas aeruginosa, and Enterobacter species) by Infectious Diseases Society of America (IDSA) in 2004 [4]. Soon afterwards it quickly developed into pan-drug resistance and has since received rapid recognition as one of the most important bacterial pathogens for healthcare-associated infections (HAIs) $[5,6]$. The increased multidrug resistance and long period nosocomial persistence of $A$. baumannii resulted in a serious threat to hospitalized patients. The hallmark of the extreme drug resistance (XDR) phenotype is carbapenems resistance (CR), accounting for the majority of $A$. baumannii strains in many hospitals today. CR strains are often resistant to all other routinely tested antibiotics, except polymyxins, tigecycline, and sometimes aminoglycoside [7-10]. Treatment of CR-A. baumannii infection therefore involves the use of combinations of last resort agents such as colistin, but their efficacy and safety are yet to be defined.

Despite the increasing importance of MDR A. baumannii in nosocomial infections, the role and mechanism of virulence factors in A. baumannii pathogenesis for human infections remain largely obscure. Recently, animal models of disease and cell infestation combined with bacterial mutagenesis have provided some valuable insights into mechanisms of A. baumannii pathogenesis. Some potential virulence factors seem to be important for disease, including outer membrane porins, surface structures including capsule and lipopolysaccharide, enzymes such as phospholipase $\mathrm{D}$, iron acquisition systems, and regulatory proteins.

These virulence factors may involve in the infection process, such as transmission, binding to host structures, cellular damage and A. baumannii invasion [11]. The propensity for biofilm formation is likely to contribute to transmission, which is the initial step in disease. Established factors that contribute to A. baumannii biofilm formation include pili (aromatic compounds, paaE [12]), outer membrane proteins (surface antigen protein 1, surA1 [13]), glycoproteins and capsular polysaccharides (O-pentasaccharide, pglC or pglL [14, 15]), and extracellular polysaccharide (Phospholipase D, pld $[16,17])$. Binding to host structures may be the first stage in the development of pneumonia. The molecular basis for such interactions is being unraveled; adhesins that mediate binding to host cells include OmpA, Bap, and Omp33-36 [18]. Following binding to host cells is cellular damage and $A$. baumannii invasion. Once inside host cells, $B a s D$ and BauA (involved in the synthesis and transport of small, iron chelating molecules called siderophores) are required for survival [3]. Bloodstream infection is a common complication of A. baumannii infection; the virulence gene traT, encoded the R6-5 plasmid-specified outer membrane protein, has previously been shown to mediate resistance to Gram-negative bacterial killing by serum [19].

Our previous surveys revealed that the antibiotic resistance among $A$. baumannii clinical isolates is very serious. [20, 21]. And antimicrobial- resistant $A$. baumannii has very high potential to spread among ill patients in ICU (intensive care units), so it is crucial to adopt early recognition and timely implementation of appropriate infection control measures in preventing outbreaks. Owing to the lack of new antimicrobials in the pipeline for problematic MDR organisms, understanding the role and mechanism of virulence factors in A. baumannii pathogenesis constitute novel therapeutic targets for rational drug design. We conducted a prospective exploratory study by investigating the prevalence of A. baumannii within a general hospital in western China, then analyzing the distribution of 9 virulence genes, and trying to explore the primary characteristics of the virulence genes within clinically MDR and non-MDR isolates of $A$. baumannii.

\section{RESULTS}

\section{Clinical information of the isolates}

To investigate the epidemiology of $A$. baumannii, a total of 88 A. baumannii clinical isolates causing nosocomial infections were identified. The clinical characteristics of the 88 patients with $A$. baumannii infections were summarized in Supplementary Table 1. Epidemiological analysis of the 88 patients carrying A. baumannii ( 56 males and 32 females) revealed that 25 were $\geq 79$ years old, 32 were between 69 and 79 years old, 17 were between 59 and 69 years old and 14 were $\leq 59$ years old (Figure 1a). This indicates that the risk of $A$. baumannii infection would be increased with compromised immunity in aging demographics. The 88 A. baumannii clinical isolates were obtained from different types of specimens including sputum $(71.6 \%$, $63 / 88)$, sputum suction $(13.6 \%, 12 / 88)$, douche $(12.5 \%$, $11 / 88)$, urine $(1 \%, 1 / 88)$ and blood $(1 \%, 1 / 88)$. Most of the clinical specimens were isolated from sputum and sputum suction, which is consistent with that $A$. baumannii is a major pathogen associated with respiratory tract infection. The most prevalent department of isolation was the Respiratory department $(37.5 \%, 33 / 88)$, followed by ICU $(23.9 \%, 21 / 88)$, Neurology department $(7.9 \%, 7 / 88)$, Cardiovascular department $(6.8 \%, 6 / 88)$, Nephrology department $(5.7 \%, 5 / 88)$, and other wards $(18.2 \%, 16 / 88)$ (Figure 1b).

\section{Genotyping of $A$. baumannii clinical isolates}

To determine the spread of $A$. baumannii within the hospital setting, all isolates were genotyped using PFGE (Pulsed Field Gel Electrophoresis). PFGE results were 
analyzed by BioNumerics and pulsotype designation was based on isolates showing $\geq 80 \%$ relatedness. PFGE fingerprinting analysis revealed that $58 \mathrm{~A}$. baumannii isolates (all $\geq 80 \%$ relatedness) were Epidemic group and the remaining $31 \mathrm{~A}$. baumannii isolates (all $<80 \%$ relatedness) were Sporadic group (Supplementary Figure 1).

The Epidemic group were classified into 13 major clusters from A to $\mathrm{M}$, in which the Larger Clusters (cluster A, D, $\mathrm{H}$ and $\mathrm{M}, \mathrm{N} \geq 5$ ) contains a total of $44.3 \%$. Cluster A $(19.3 \%, 17 / 88)$ was most frequently detected in the clinical isolates and was responsible for an epidemic between January and February in 2014, and in the Respiratory department $(\mathrm{N}=9)$, ICU $(\mathrm{N}=5)$, Internal Medicine Ward $(\mathrm{N}=1)$, General surgery ward $(\mathrm{N}=1)$ and Cardiovascular department $(\mathrm{N}=1)$. Cluster D $(12.5 \%$, $11 / 88$ ) was second most frequent that detected in the clinical isolates and was closely correlated in August ( $\mathrm{N}$ $=3)$, July $(\mathrm{N}=1)$ and September $(\mathrm{N}=1)$ in 2014 and January $(\mathrm{N}=3)$, August $(\mathrm{N}=2)$ and July $(\mathrm{N}=1)$ in 2015, with a source of Respiratory department $(\mathrm{N}=6)$, ICU $(\mathrm{N}=3)$, Nephrology department $(\mathrm{N}=1)$ and Neurology department $(\mathrm{N}=1)$. Cluster $\mathrm{H}(6.8 \%, 6 / 88)$ was closely correlated with April $(\mathrm{N}=5)$ and July $(\mathrm{N}=1)$ in 2014, and comes from the ICU $(\mathrm{N}=3)$, Respiratory department $(\mathrm{N}=1)$, Geriatric Medicine $(\mathrm{N}=1)$ and Cardiovascular department $(\mathrm{N}=1)$. Cluster $\mathrm{M}(5.7 \%, \mathrm{~N}=5)$ was closely correlated with December in $2013(\mathrm{~N}=4)$ and August in 2014 , and distributed in the Respiratory department $(\mathrm{N}=$ $2)$, ICU $(\mathrm{N}=2)$ and Digestive System Department $(\mathrm{N}=$ 1) (Supplementary Table 1). Although a small proportion of these Larger Clusters were discretely distributed at different wards, most of the strains were found within were mainly concentrated in respiratory and ICU wards (Figure 1c).

\section{Antimicrobial susceptibility of $A$. baumannii clinical isolates}

To understand the drug-resistance of $88 \mathrm{~A}$. baumannii clinical isolates, antimicrobial susceptibility testing was performed. The results showed that the resistance rates to levofloxacin, ciprofloxacin, gentamicin, amikacin, tobramycin, minocycline, doxycycline, meropenem, imipenem and polymyxin B accounted for 34.1\% (30/88), $68.2 \%$ (60/88), 67.0\% (59/88), 58.0\% (51/88), 58.0\% (51/88), 1.1\% (1/88), 67.0\% (59/88), 54.5\% (48/88), 65.9\% $(58 / 88)$ and $0 \%(0 / 88)$, respectively (Table 1$)$. The resistance rates of ciprofloxacin, gentamicin, amikacin, tobramycin, doxycycline, meropenem and imipenem were all above 50\%, while those of levofloxacin, polymyxin B and minocycline
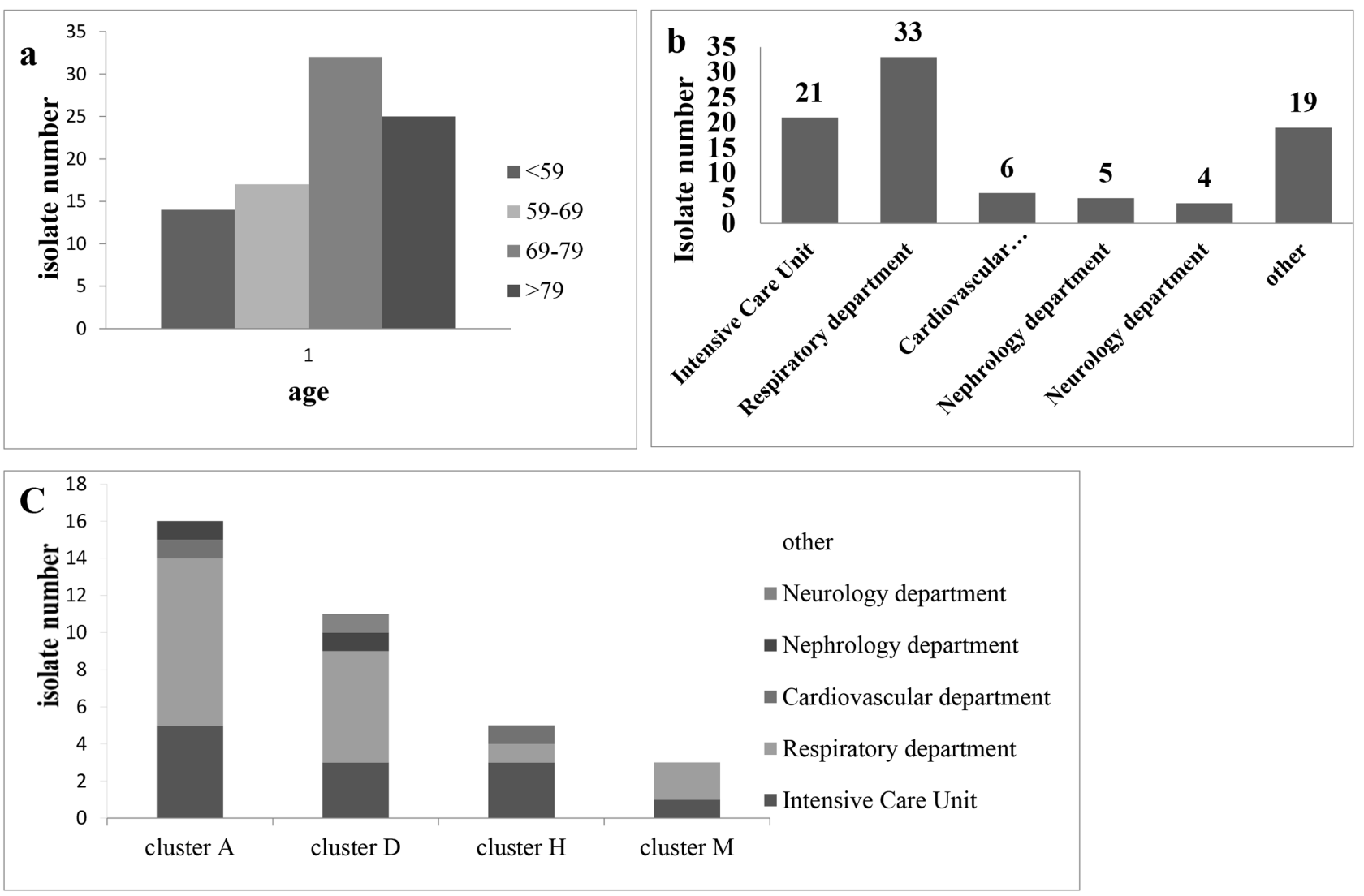

Figure 1: (a) Distribution of the age of biocides for 88 clinical isolates of $A$. baumannii. (b) The source distribution for 88 clinical of $A$. baumannii. (c) Distribution of the source for the larger cluster (A, D, H and M). 
Table 1: Data of $A$. baumannii isolates resistant to selected antibiotics and genotyping

\begin{tabular}{|c|c|c|c|c|c|c|c|c|}
\hline \multirow{3}{*}{ Antimicrobial agents } & \multirow{3}{*}{$\frac{\text { All }}{88(\%)}$} & \multicolumn{4}{|c|}{ Larger Clusters $(\mathrm{N}=39)$} & \multirow{3}{*}{$\begin{array}{l}\text { Epidemic } \\
58(n, \%)\end{array}$} & \multirow{3}{*}{$\begin{array}{l}\text { Sporadic } \\
30(n, \%)\end{array}$} & \multirow{3}{*}{ P value } \\
\hline & & Cluster A & Cluster D & Cluster $\mathbf{H}$ & Cluster M & & & \\
\hline & & $17(\%)$ & $11(\%)$ & $6(\%)$ & $5(\%)$ & & & \\
\hline LEV & 34.1 & 58.8 & 45.5 & 33.3 & 60.0 & $28,48.3$ & $2,6.7$ & $<0.000$ \\
\hline CIP & 68.2 & 94.1 & 90.9 & 100 & 80.0 & $51,87.9$ & 9,30 & $<0.000$ \\
\hline MIN & 1.1 & 0 & 0 & 0 & 20.0 & $1,1.7$ & 0 & 1 \\
\hline DOX & 67.0 & 100 & 90.9 & 100 & 80.0 & $51,87.9$ & $8,26.7$ & $<0.000$ \\
\hline AMK & 58.0 & 100 & 54.5 & 100 & 60.0 & $47,81.0$ & $4,13.3$ & $<0.000$ \\
\hline GEN & 67.0 & 100 & 63.6 & 100 & 80.0 & $49,84.5$ & $10,33.3$ & $<0.000$ \\
\hline TOB & 58.0 & 94.1 & 54.5 & 100 & 60.0 & $45,77.6$ & 6,20 & $<0.000$ \\
\hline MERO & 54.5 & 94.1 & 72.7 & 100 & 60.0 & $43,74.1$ & $5,16.7$ & $<0.000$ \\
\hline IMP & 65.9 & 100 & 90.9 & 100 & 60.0 & $50,86.2$ & $8,26.7$ & $<0.000$ \\
\hline PB & 0 & 0 & 0 & 0 & 0 & 0 & 0 & \\
\hline MDR & 52.3 & 94.1 & 54.5 & 100 & 60.0 & $44,75.9$ & $2,6.7$ & $<0.000$ \\
\hline
\end{tabular}

LEV, Levofloxacin; CIP, Ciprofloxacin; MIN, Minocycline; DOX, Doxycycline; AMK, Amikacin; GEN, Gentamicin; TOB, Tobramycin; IMP, Imipenem; MERO, Meropenem; Polymyxin B, PB; MDR, Multidrug resistance; P value, Chi-square test or Fisher exact test. Larger Clusters mean clusters contains a larger number of strains $(\mathrm{N} \geq 5)$.

were only $34.1 \%, 0 \%$ and $1.1 \%$, respectively. Most importantly, in the Larger Clusters (cluster A, D, H and M), the rates of resistance to some antibiotics were almost over $80 \%$ (Table 1). From these results we can reasonably infer that minocycline and polymyxin B may be used as empiric treatment agents for A. baumannii in China. Interestingly, the resistance rate of all the antibiotics in the Epidemic group was significantly higher than that of the Sporadic group, except for minocycline and polymyxin $\mathrm{B}$ ( $\mathrm{P}$ value $<0.05$ ).

For cross-resistance profile in these isolates, we found that the prevalence of MDR A. baumannii isolates was $52.3 \%(46 / 88)$ in the present study. Combined with the genotype data of these $88 \mathrm{~A}$. baumannii isolates, the resistance rate of MDR A. baumannii in the Sporadic group was only $6.7 \%(2 / 30)$ (P value $<0.01$, Table 1$)$. On the contrary, MDR A. baumannii isolates almost predominated in the Epidemic group, and A. baumannii isolates in cluster $\mathrm{A}(94.1 \%, 16 / 17)$ and cluster $\mathrm{H}(100 \%$, 6/6) were almost all MDR. Above all, the high proportion of MDR A. baumannii in the Epidemic group indicated that MDR A. baumannii is more likely to spread and cause infection in the hospital.

\section{Prevalence of virulence genes among A. baumannii}

To investigate the virulence potential of 88 A. baumannii clinical isolates, PCR was conducted to detected 9 virulence associated genes (mentioned in the
Introduction section and listed in Table 2). The results showed that the virulence genes bap $(95.5 \%, 84 / 88)$, surA1 (92.0\%, 81/88), BasD (92.0\%, 81/88), paaE $(88.6 \%, 78 / 88)$ and pld $(87.5 \%, 77 / 88)$ were accounted for high proportion ( $>80 \%)$ in these $88 \mathrm{~A}$. baumannii isolates. Meanwhile, more than half of the clinical isolates carried BauA (62.5\%, 55/88), omp33-36 (59.1\%, 52/88) and $p g l C$ (53.4\%, 47/88). However, no traT (serum resistance gene) were detected in these A. baumannii isolates (Table 3).

Associated with the drug-resistance of $88 \mathrm{~A}$. baumannii clinical isolates, the results revealed that the distribution of each virulence associated gene has some unique characteristics. The rate of surAl among aminoglycosides (tobramycin and amikacin), doxycycline and carbapenems (imipenem and meropenem) resistant isolates was significantly higher than that in homologous sensitive isolates. The rate of BauA among the vast majority of antibiotics resistant (levofloxacin, ciprofloxacin, gentamicin, tobramycin, amikacin, doxycycline, imipenem and meropenem) isolates was significantly higher than that of homologous sensitive isolates. The rate of pld among doxycycline, aminoglycosides and carbapenem resistant isolates was significantly higher than that of homologous sensitive isolates. The rate of paaE among ciprofloxacin, gentamicin, tobramycin, amikacin, doxycycline, imipenem and meropenem resistant isolates was significantly higher than that of homologous sensitive isolates. But 
Table 2: Virulence genes among multidrug resistance and genotyping Acinetobacter baumannii strains isolated

\begin{tabular}{|c|c|c|c|c|c|c|c|c|c|c|c|}
\hline & $\begin{array}{c}\text { All } \\
(\mathrm{n}, \%)\end{array}$ & $\begin{array}{c}\text { cluster } A \\
(\mathrm{~N}=17)\end{array}$ & $\begin{array}{c}\text { cluster D } \\
(\mathrm{N}=11)\end{array}$ & $\begin{array}{c}\text { cluster } \\
\mathbf{H}(\mathrm{N}=6)\end{array}$ & $\begin{array}{c}\text { cluster } \\
\mathbf{M}(\mathbf{N}=\mathbf{5})\end{array}$ & $\begin{array}{c}\text { MDR } \\
(\mathrm{N}=46) \\
(\mathrm{n}, \%)\end{array}$ & $\begin{array}{c}\text { non- MDR } \\
(\mathrm{N}=42) \\
(\mathrm{n}, \%)\end{array}$ & $\begin{array}{c}P \\
\text { value }\end{array}$ & $\begin{array}{c}\text { Epidemic } \\
\mathrm{N}=\mathbf{5 8} \\
(\mathrm{n}, \%)\end{array}$ & $\begin{array}{c}\text { Sporadic } \\
\mathbf{N}=\mathbf{3 0} \\
(\mathbf{n}, \%)\end{array}$ & $P$ value \\
\hline bap & $84,95.5$ & 100 & 100 & 100 & 80.0 & $45,97.8$ & $39,92.9$ & 0.545 & $57,98.3$ & $27,90.0$ & 0.22 \\
\hline surA1 & $81,92.0$ & 100 & 100 & 100 & 60.0 & 46,100 & $35,83.3$ & 0.004 & $55,94.5$ & $26,86.8$ & 0.355 \\
\hline BasD & $81,92.0$ & 100 & 100 & 100 & 60.0 & $44,95.7$ & $37,88.1$ & 0.361 & $55,94.5$ & $26,86.9$ & 0.071 \\
\hline BauA & $55,62.5$ & 88.2 & 72.7 & 83.3 & 60.0 & $36,78.3$ & $19,45.2$ & 0.001 & $44,75.9$ & $11,36.7$ & $<0.000$ \\
\hline pld & $77,87.5$ & 100 & 100 & 100 & 40.0 & $44,95.7$ & $33,78.6$ & 0.016 & $53,91.4$ & 24,80 & 0.234 \\
\hline $\begin{array}{l}\text { omp- } \\
33-36\end{array}$ & $52,59.1$ & 52.9 & 63.6 & 66.7 & 40.0 & $26,56.5$ & $26,61.9$ & 0.608 & $29,50.0$ & $23,76.7$ & 0.016 \\
\hline paaE & $78,88.6$ & 100 & 90.9 & 100 & 60.0 & $45,97.8$ & $33,78.6$ & 0.012 & $54,93.1$ & 24,80 & 0.138 \\
\hline$p g l C$ & $47,53.4$ & 41.2 & 72.7 & 16.7 & 60.0 & $21,45.7$ & $26,61.9$ & 0.127 & $31,53.4$ & $16,53.3$ & 0.992 \\
\hline $\operatorname{tra} T$ & 0 & 0 & 0 & 0 & 0 & 0 & 0 & & 0 & 0 & \\
\hline
\end{tabular}

Table 3: Virulence genes among antibiotic resistance and sensitive of Acinetobacter baumannii strains isolated

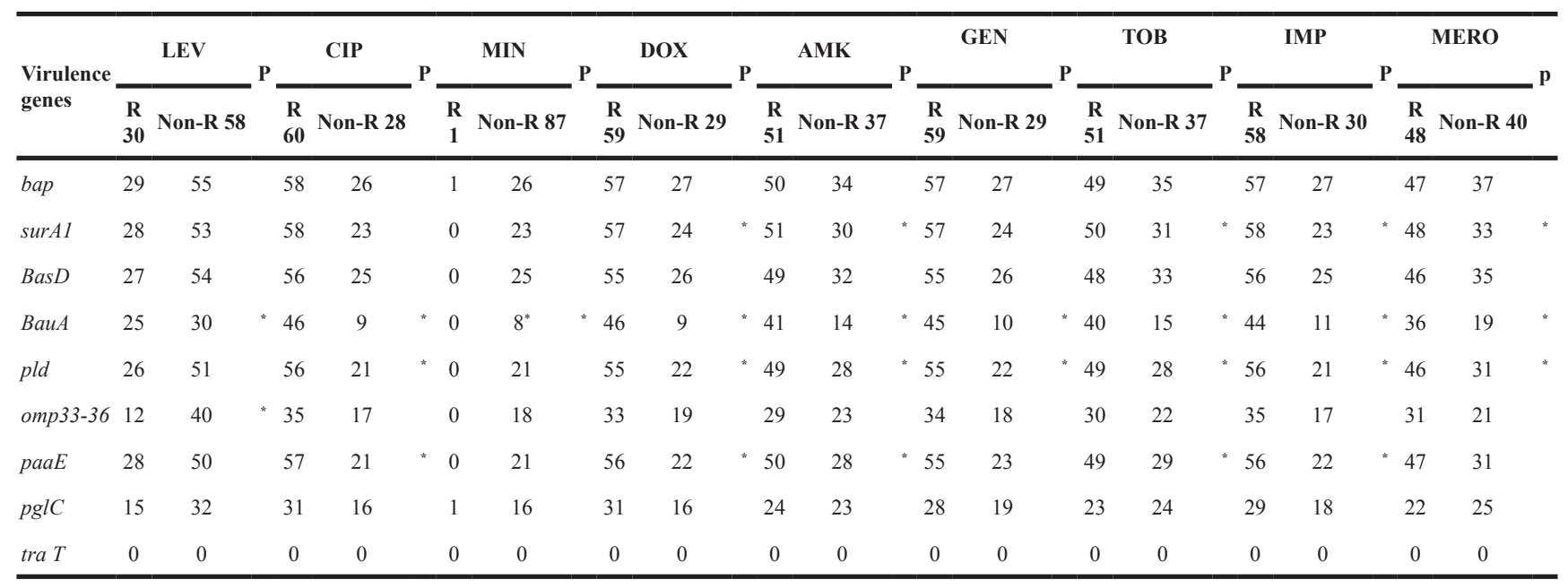

LEV, Levofloxacin; CIP, Ciprofloxacin; MIN, Minocycline; DOX, Doxycycline; AMK, Amikacin; GEN, Gentamicin; TOB, Tobramycin; IMP, Imipenem; MERO, Meropenem; R, Resistant; non-R, non- resistant; P, P value, Chi-square test or Fisher exact test; ", P value $<0.05$; Same as in Table 2.

what's interesting is that the rate of omp33-36 among levofloxacin sensitive isolates was significantly higher than that of levofloxacin resistance isolates. In summary, these relationships are statistically significant $(\mathrm{P}$ value $<0.05$ ) (Table 4), and the antibiotic-resistant $A$. baumannii carries more virulence genes.

Further analysis in cross-resistance profile found that, the carriage ratio of surA1, BauA, pld and paaE in MDR A. baumannii isolates $(100.0 \%, 78.3 \%, 95.7 \%$, $97.8 \%$ ) was significantly higher (P value $<0.05)$ than in non-MDR A. baumannii isolates (83.3\%, 45.2\%, 78.6\%, $78.6 \%$ ), and the carriage ratio of BasD in Epidemic isolates $(94.5 \%)$ was significantly higher $(\mathrm{P}$ value $<0.05$ ) than in Sporadic isolates (86.9\%) (Table 3).

\section{DISCUSSION}

Acinetobacter spp. was initially considered as an opportunistic human pathogen of low virulence with minimal significance. However, during the last two decades, the increasing ubiquity and intensity of mechanical ventilation, central venous and urinary catheterization, and antibacterial therapy have caused a surge in the frequency and severity of Acinetobacter infections [22-24]. A. baumannii is endowed with an open pan genome, which means it can easily acquire new function. The persistence of $A$. baumannii in the hospital setting, together with the strong selection pressure imposed by the use of antimicrobials in the 
Table 4: Virulence genes primer used in this study and the protein functions

\begin{tabular}{|c|c|c|c|}
\hline Virulence gene & Nucleotide sequence & Protein function/description & Reference \\
\hline bap & $\begin{array}{l}\text { F: AGTTAAAGAAGGGCAAGAAG } \\
\text { R: GGAGCACCACCTAACTGA }\end{array}$ & Biofilm maturation, maintenance & {$[54]$} \\
\hline surAl & $\begin{array}{l}\text { F: CAATTGGTAGCTGGCGATCA } \\
\text { R: TTAGGCGGGACTCAGCTTTT }\end{array}$ & Surface antigen protein 1 & [13] \\
\hline$B a s D$ & $\begin{array}{l}\text { F: CTCTTGCATGGCAACACCAC } \\
\text { R: CCAACGAGACCGCTTATGGT }\end{array}$ & $\begin{array}{l}\text { Acinetobactin biosynthesis } \\
\text { Iron acquisition system }\end{array}$ & {$[55,56]$} \\
\hline BauA & $\begin{array}{l}\text { F: TGGCAAGGTGAAAATGCACG } \\
\text { R: GCCGCATATGCCATCAACTG }\end{array}$ & $\begin{array}{l}\text { Acinetobactin transport } \\
\text { Iron acquisition system }\end{array}$ & \\
\hline Pld & $\begin{array}{l}\text { F: CCGTCAATTACGCCAAGCTG } \\
\text { R: CTGACGCTACCTGACGGTTT }\end{array}$ & Phospholipase D & {$[57,58]$} \\
\hline omp33-36 & $\begin{array}{l}\text { F: ATTAGCCATGACCGGTGCTC } \\
\text { R: CCACCCCAAACATGGTCGTA }\end{array}$ & Outer membrane porin & {$[59-61]$} \\
\hline paaE & $\begin{array}{l}\text { F: CTATTTAGGCGTTGCTGCGG } \\
\text { R: CCTTACAACGACAGGTCGCA }\end{array}$ & phenylalanine catabolic pathway & {$[62,63]$} \\
\hline$p g l C$ & $\begin{array}{l}\text { F: TGGATGAGTTAGCTGC } \\
\text { R: TTTTACAAATAGTTAAGC }\end{array}$ & $\begin{array}{l}\text { O-glycosylation system } \\
\text { capsular polysaccharide }\end{array}$ & {$[14,64]$} \\
\hline $\operatorname{traT}$ & $\begin{array}{l}\text { F: GGTGTGGTGCGATGAGCACAG } \\
\text { R: CACGGTTCAGCCATCCCTGAG }\end{array}$ & Serum-resistance-associated & {$[65]$} \\
\hline
\end{tabular}

clinical practice, has promoted the evolution of clinical A. baumannii towards drug resistance isolates and the formation of some virulence factors which facilitate the survival of $A$. baumannii in the hospital [25].

Drug-resistant $A$. baumannii is more likely to survive in hospital environment, causing an outbreak in the hospital $[26,27]$. The treatment of $A$. baumannii infections is becoming a serious problem because of its strong antibiotic resistance [28]. Especially, surveillance by the CHINET project demonstrated that resistance of A. baumannii strains to carbapenems increased from 31 to $66.7 \%$ between 2005 and 2014 [29]. The current data showed that the resistance rate of imipenem $(65.9 \%$, Table 1) was higher than our previous report (60.9\%) [10]. Although the resistance rate is lower than in Turkey (94.9\%) [30] and Iran (82\%) [31], it is still in a rising tendency. This suggests that carbapenems can't be habitually used in A. baumannii infectious treatment.

Here, we found that the MDR $A$. baumannii in the Epidemic group $(44 / 58,75.9 \%)$ was higher than that of Sporadic group $(2 / 30,6.7 \%)$ (P value $<0.05$, Table 1$)$. In addition, the Larger Clusters $\mathrm{A}, \mathrm{D}, \mathrm{H}$ and $\mathrm{M}$ in the Epidemic group are all substantially composed of MDR $A$. baumannii, and showed resistance to most of the antibiotics. This result may due to the clinical abuse of antibiotics, and resistant $A$. baumanii was screened to survive, and then gradually developed into MDR $A$. baumannii. So, their persistent selection and ongoing transmission in hospital may result in epidemic outbreak $[32,33]$.
Traditional thinking was that antibiotic resistance caused a metabolic cost to the bacterium and hence the "anti-virulence" factor [34]. However, the White paper reported that a lung and blood clinical isolate (A. baumannii HUMC1) is not only an extreme drugresistant isolate (almost resistant to all antibiotics, except colistin), but also a hyper-virulent isolate [35]. Meanwhile, some researchers have also suggested that MDR $A$. baumannii can survive proliferation even after the host treated with antibiotics, and then producing a variety of metabolites that upset the physiological balance of the host as a virulence effect $[13,36]$. Accordingly, the clinical outcome of $A$. baumannii infections is jointly influenced by antimicrobial resistance and virulence factor.

The infection symptoms caused by $A$. baumannii are closely associated with its virulence factor. But the virulence genes distribution in clinical A. baumannii were rarely reported, except for bap, omp33-36 and traT [37, 38]. This work examined the distribution of 9 virulence genes in clinically collected A. baumannii isolates. Our results showed that the existence rate of each virulence gene in the A. baumannii isolates was more than $50 \%$, except traT (Table 3). Furthermore, the virulence genes carriage rate of $A$. baumannii in MDR was significantly higher than that of non-MDR A. baumannii $(\mathrm{P}<0.05$, Table 3), such as $\operatorname{surA1}$, BauA, pld and paaE. This suggests that the drug resistant $A$. baumannii isolates appear to have greater potentials for toxicity.

Biofilm is an important virulence factor of $A$. baumannii. Loehfelm et al. suggested the development and 
thickness of the mature biofilm structure and intercellular adhesion were closely associated with Bap family proteins (coded gene bap) [39]. The bap genes were detected with very high frequency in clinical $A$. baumannii from Iran (92\%) [40], Republic of Korea (100\%) [37] and USA (84\%) [41]. This work also showed that A. baumannii isolates frequently possess bap genes (95.5\%). These results indicate that most $A$. baumannii may have the biofilm formation ability.

Baumannii acinetobactin utilization (BauA) is an outer membrane protein, acting out the siderophore-ferric complex receptor [42]. Whole protein includes 2 domains comprising a cork domain at $\mathrm{N}$ terminal of the protein and a transmembrane barrel at the $\mathrm{C}$ terminal [43]. This work showed the rate of virulence gene $B a u A$ was significantly higher in drug-resistant $A$. baumannii $(\mathrm{P}<0.05$, Table 4$)$, and $A$. baumannii isolates with BauA gene seems to show a wide range of drug resistance. So, we speculate that the transmembrane barrel may be associated with drug resistance in $A$. baumannii.

A. baumannii phenylacetate degradation pathway was a hybrid pathway [12], and a key step in this pathway is performed by the paaE gene [44]. This study indicates that the rates of $p a a E$ were higher in the ciprofloxacin, tobramycin, amikacin, doxycycline or imipenem resistant A. baumannii isolates than in the corresponding sensitive isolates $(\mathrm{P}<0.05$, Table 4$)$. We speculate these antibiotics may be metabolized as substrates during the metabolism of phenylacetic.

Some recent studies have reported that the virulence gene omp33-36 contributes to resistance to carbapenems in A. baumannii [45-47]. But in our work, there was no significant difference in the frequency of omp33-36 gene carried between carbapenems-resistant and -sensitive $A$. baumannii (Table 4). In contrast, our work showed that $A$. baumannii, which was found to be levofloxacin-sensitive, appears to carry more virulence gene omp33-36, and only a few $A$. baumannii isolates developed resistance to levofloxacin. We think levofloxacin is an effective drug for the treatment of $A$. baumannii infection.

A recent study reported that $\operatorname{traT}(80 \%)$ was found high frequency in CR-A. baumannii isolates in Iran [38]. However, this study showed that none of the $88 \mathrm{~A}$. baumannii clinical isolates carried the traT gene, which was similar to the report of Brasil, 2004 [48]. This indicates that traT gene frequently existing in CR-A. baumannii is not a universal phenomenon, for the moment only finding in Iran.

In summary, our findings showed that the prevalence of MDR A. baumannii isolates collected from different wards was $52.3 \%$, and the MDR A. baumannii in the Epidemic group was significant higher than that of Sporadic group. Virulence associated genes detected in this study accounted for a high proportion among the $88 \mathrm{~A}$. baumannii clinical isolates, especially in the MDR A. baumannii isolates, which means high risk, high pathogenicity and high treatment challenge. At the same time, our work indicates that some potential links between virulence genes and drug resistance. This work strongly suggests that hospitals need to strengthen infection control to prevent $A$. baumannii from causing an outbreak of infection.

\section{MATERIALS AND METHODS}

\section{Bacterial isolates and growth conditions}

The 88 nonrecurring clinical isolates of $A$. baumannii used in this study were collected from patients with nosocomial infections during the period from April 2013 to October 2015, at the First Affiliated Teaching Hospitals of Chengdu Medical College in Sichuan province, China. All isolates were collected as part of routine care, data were collected, identified and handled anonymously. The strains were stored in glycerol at $-80^{\circ} \mathrm{C}$ and bacteria were grown on MacConkey Agar (MCA plates) (Oxoid, England) before tested. Isolates were identified by VITEK 2 (bioMe'rieux, Marcy-l'E'toile, France) automated microbiology system. Besides, all isolates were further verified by detecting the existence of the $r p o B$ and sequencing the $16 S-23 S$ rRNA gene spacer region [10].

\section{Pulsed-field gel electrophoresis testing}

All the $88 \mathrm{~A}$. baumannii isolates were genotyped by using Pulsed-Field Gel Electrophoresis (PFGE) analysis as previously described [49]. A. baumannii isolates were grown on Mueller-Hinton agar medium plates overnight at $37^{\circ} \mathrm{C}$ and bacterial genomic DNAs were prepared. After the genomic DNA was digested with ApaI (TaKaRa, Dalian, China), the DNA fragments were separated by electrophoresis in $1 \%$ gold agarose (Lonza) in $0.5 \times$ Tris - borate - EDTA buffer with a CHEF apparatus (CHEF Mapper XA, Bio-Rad, USA). The conditions included $14^{\circ} \mathrm{C}$ and $6 \mathrm{~V} / \mathrm{cm}$ with alternating pulses at a $120^{\circ}$ angle with a 5-35s pulse time gradient for a total of $22 \mathrm{~h}$. The same method was also used to extract the Salmonella enterica serotype Braenderup H9812 genomic DNAs, which was used as the size marker after being digested by XbaI (TaKaRa, Dalian, China) [50]. The similarity examination of DNA patterns analyzed with BioNumerics 7.0 (Applied Math, USA) was based on Tenover criteria and Dice coefficient, and $80 \%$ relatedness was used as the threshold to distinguish the pulsotype [51].

\section{Antimicrobial susceptibility testing}

The $88 \mathrm{~A}$. baumannii strains were tested for their susceptibilities to 10 antibiotics: levofloxacin, ciprofloxacin, gentamicin, amikacin, tobramycin, minocycline, doxycycline, meropenem, imipenem and polymyxin B. The minimal inhibitory concentrations (MICs) were determined by agar dilution method and interpreted as previously described in the guidelines according to the 2017 Clinical and Laboratory Standards 
Institute (CLSI) [52]. Escherichia coli ATCC 25922 and Pseudomonas aeruginosa ATCC 27853 were both used as quality control strains. The MICs value used to indicate antibiotic resistance are $\geq 4 \mu \mathrm{g} / \mathrm{ml}$ for ciprofloxacin and polymyxin $\mathrm{B}$ in accordance with CLSI, $\geq 8 \mu \mathrm{g} / \mathrm{ml}$ for levofloxacin, meropenem and imipenem, $\geq 16 \mu \mathrm{g} / \mathrm{ml}$ for gentamicin, tobramycin, minocycline and doxycycline, and $\geq 64 \mu \mathrm{g} / \mathrm{ml}$ for amikacin.

\section{Definition of multidrug resistance (MDR)}

Base on researchers' definition of MDR among $A$. baumannii in many published works [53], we defined MDR A. baumannii as containing resistance to any combination of 3 or more of the 4 drug classes commonly used to treat Gram negative infections: fluoroquinolones, aminoglycosides, carbapenems and tetracyclines. Resistance to an antibiotic class was defined as resistance to all drugs representative of that class in this panel.

\section{PCR amplification and DNA sequencing for virulence genes detecting}

9 virulence genes as listed in Table 2 were detected by PCR to investigate the distribution in the $88 \mathrm{~A}$. baumannii strains. The primers used were also listed in Table 2 and PCR was carried out according to references in the same table. The PCR products were sequenced by TSINGKE (Chengdu, China) and then confirmed by sequence alignment to the corresponding genes of $A$. baumannii with NCBI Nucleotide Blast (http://blast.ncbi. nlm.nih.gov/Blast.cgi)

\section{Author contributions}

C.L and Y.C have contributed equally to this work. R.W and X.J conceived and designed the study. C.L, Y.C, Y.X, Y.L, L.W, Z.M and S.L performed the experiments. C.L, Y.C, R.W and X.J analyzed the data and wrote the manuscript. All authors reviewed and approved the final version of the manuscript.

\section{CONFLICTS OF INTEREST}

The authors declare that there are no competing interests regarding the publication of this paper.

\section{FUNDING}

This work was supported by grants from the National Natural Science Foundation of China (grants 31470246, 31701078 and 31300659), Scientific Research and Innovation Team of Sichuan Province (grant 15TD0025), Preeminent Youth Fund of Sichuan Province (grant 2015JQO019) and Huiming Project of Chengdu Science and Technology Bureau (grant 2015-HM0100543-SF).

\section{REFERENCES}

1. Lin MF, Lan CY. Antimicrobial resistance in Acinetobacter baumannii: From bench to bedside. World J Clin Cases. 2014; 2:787-814. https://doi.org/10.12998/wjcc.v2.i12.787.

2. Villegas MV, Hartstein AI. Acinetobacter outbreaks, 1977 2000. Infect Control Hosp Epidemiol. 2003; 24:284-95. https://doi.org/10.1086/502205.

3. Gaddy JA, Arivett BA, McConnell MJ, Lopez-Rojas R, Pachon J, Actis LA. Role of acinetobactin-mediated iron acquisition functions in the interaction of Acinetobacter baumannii strain ATCC 19606 T with human lung epithelial cells, Galleria mellonella caterpillars, and mice. Infect Immun. 2012; 80:1015-24. https://doi.org/10.1128/ IAI.06279-11.

4. Boucher HW, Talbot GH, Bradley JS, Edwards JE, Gilbert D, Rice LB, Scheld M, Spellberg B, Bartlett J. Bad bugs, no drugs: no ESKAPE! An update from the Infectious Diseases Society of America. Clinical Infectious Diseases. 2009; 48:1. https://doi.org/10.1086/595011.

5. Falagas ME, Bliziotis IA. Pandrug-resistant Gramnegative bacteria: the dawn of the post-antibiotic era? Int J Antimicrob Agents. 2007; 29:630-6. https://doi. org/10.1016/j.ijantimicag.2006.12.012.

6. Falagas ME, Rafailidis PI. Attributable mortality of Acinetobacter baumannii: no longer a controversial issue. Crit Care. 2007; 11:134. https://doi.org/10.1186/cc5911.

7. Freire MP, de Oliveira Garcia D, Garcia CP, Campagnari Bueno MF, Camargo CH, Kono Magri AS, Francisco GR, Reghini R, Vieira MF, Ibrahim KY, Rossi F, Hajjar L, Levin AS, et al. Bloodstream infection caused by extensively drug-resistant Acinetobacter baumannii in cancer patients: high mortality associated with delayed treatment rather than with the degree of neutropenia. Clin Microbiol Infect. 2016; 22:352-8. https://doi.org/10.1016/j.cmi.2015.12.010.

8. Chopra T, Marchaim D, Johnson PC, Awali RA, Doshi H, Chalana I, Davis N, Zhao JJ, Pogue JM, Parmar S, Kaye KS. Risk factors and outcomes for patients with bloodstream infection due to Acinetobacter baumannii-calcoaceticus complex. Antimicrob Agents Chemother. 2014; 58:4630-5. https://doi.org/10.1128/aac.02441-14.

9. Chopra T, Marchaim D, Awali RA, Krishna A, Johnson P, Tansek R, Chaudary K, Lephart P, Slim J, Hothi J, Ahmed H, Pogue JM, Zhao JJ, et al. Epidemiology of bloodstream infections caused by Acinetobacter baumannii and impact of drug resistance to both carbapenems and ampicillinsulbactam on clinical outcomes. Antimicrob Agents Chemother. 2013; 57:6270-5. https://doi.org/10.1128/ aac.01520-13.

10. Chang Y, Luan G, Xu Y, Wang Y, Shen M, Zhang C, Zheng W, Huang J, Yang J, Jia X, Ling B. Characterization of carbapenem-resistant Acinetobacter baumannii isolates in a Chinese teaching hospital. Front Microbiol. 2015; 6:910. https://doi.org/10.3389/fmicb.2015.00910. 
11. Doi Y, Murray GL, Peleg AY. Acinetobacter baumannii: evolution of antimicrobial resistance-treatment options. Semin Respir Crit Care Med. 2015; 36:85-98. https://doi. org/10.1055/s-0034-1398388.

12. Cerqueira GM, Kostoulias $\mathrm{X}$, Khoo C, Aibinu I, Qu Y, Traven A, Peleg AY. A global virulence regulator in Acinetobacter baumannii and its control of the phenylacetic acid catabolic pathway. J Infect Dis. 2014; 210:46-55. https://doi.org/10.1093/infdis/jiu024.

13. Liu D, Liu ZS, Hu P, Cai L, Fu BQ, Li YS, Lu SY, Liu NN, Ma XL, Chi D, Chang J, Shui YM, Li ZH, et al. Characterization of surface antigen protein 1 (SurA1) from Acinetobacter baumannii and its role in virulence and fitness. Vet Microbiol. 2016; 186:126-38. https://doi. org/10.1016/j.vetmic.2016.02.018.

14. Lees-Miller RG, Iwashkiw JA, Scott NE, Seper A, Vinogradov E, Schild S, Feldman MF. A common pathway for O-linked protein-glycosylation and synthesis of capsule in Acinetobacter baumannii. Mol Microbiol. 2013; 89:81630. https://doi.org/10.1111/mmi.12300.

15. Iwashkiw JA, Seper A, Weber BS, Scott NE, Vinogradov E, Stratilo C, Reiz B, Cordwell SJ, Whittal R, Schild S, Feldman MF. Identification of a general O-linked protein glycosylation system in Acinetobacter baumannii and its role in virulence and biofilm formation. PLoS Pathog. 2012; 8:e1002758. https://doi.org/10.1371/journal.ppat.1002758.

16. Stahl J, Bergmann H, Gottig S, Ebersberger I, Averhoff B. Acinetobacter baumannii Virulence Is Mediated by the Concerted Action of Three Phospholipases D. PLoS One. 2015; 10:e0138360. https://doi.org/10.1371/journal. pone. 0138360 .

17. Jacobs AC, Hood I, Boyd KL, Olson PD, Morrison JM, Carson S, Sayood K, Iwen PC, Skaar EP, Dunman PM. Inactivation of phospholipase D diminishes Acinetobacter baumannii pathogenesis. Infect Immun. 2010; 78:1952-62. https://doi.org/10.1128/iai.00889-09.

18. Longo F, Vuotto C, Donelli G. Biofilm formation in Acinetobacter baumannii. New Microbiol. 2014; 37:119-27.

19. Montenegro MA, Bitter-Suermann D, Timmis JK, Aguero ME, Cabello FC, Sanyal SC, Timmis KN. traT gene sequences, serum resistance and pathogenicity-related factors in clinical isolates of Escherichia coli and other gram-negative bacteria. J Gen Microbiol. 1985; 131:151121. https://doi.org/10.1099/00221287-131-6-1511.

20. Wang Y, Shen M, Yang J, Dai M, Chang Y, Zhang C, Luan G, Ling B, Jia X. Prevalence of carbapenemases among high-level aminoglycoside-resistant Acinetobacter baumannii isolates in a university hospital in China. Exp Ther Med. 2016; 12:3642-52. https://doi.org/10.3892/ etm.2016.3828.

21. Shen M, Luan G, Wang Y, Chang Y, Zhang C, Yang J, Deng S, Ling B, Jia X. Coexistence of blaOXA-23 with armA in quinolone-resistant Acinetobacter baumannii from a Chinese university hospital. Diagn Microbiol
Infect Dis. 2016; 84:230-1. https://doi.org/10.1016/j. diagmicrobio.2015.10.009.

22. Spellberg B, Bonomo RA. The deadly impact of extreme drug resistance in Acinetobacter baumannii. Crit Care Med. 2014; 42:1289-91. https://doi.org/10.1097/ ccm.0000000000000181.

23. Maragakis LL, Perl TM. Acinetobacter baumannii: epidemiology, antimicrobial resistance, and treatment options. Clin Infect Dis. 2008; 46:1254-63. https://doi. org/10.1086/529198.

24. Joly-Guillou ML. Clinical impact and pathogenicity of Acinetobacter. Clinical Microbiology \& Infection. 2005; 11:868.

25. Imperi F, Antunes LC, Blom J, Villa L, Iacono M, Visca P, Carattoli A. The genomics of Acinetobacter baumannii: insights into genome plasticity, antimicrobial resistance and pathogenicity. IUBMB Life. 2011; 63:1068-74. https://doi. org/10.1002/iub.531.

26. Cheng A, Chuang YC, Sun HY, Sheng WH, Yang CJ, Liao CH, Hsueh PR, Yang JL, Shen NJ, Wang JT, Hung CC, Chen YC, Chang SC. Excess Mortality Associated With Colistin-Tigecycline Compared With ColistinCarbapenem Combination Therapy for Extensively Drug-Resistant Acinetobacter baumannii Bacteremia: A Multicenter Prospective Observational Study. Crit Care Med. 2015; 43:1194-204. https://doi.org/10.1097/ ccm.0000000000000933.

27. Villalon P, Valdezate S, Cabezas T, Ortega M, Garrido N, Vindel A, Medina-Pascual MJ, Saez-Nieto JA. Endemic and epidemic Acinetobacter baumannii clones: a twelveyear study in a tertiary care hospital. BMC Microbiol. 2015; 15:47. https://doi.org/10.1186/s12866-015-0383-y.

28. Hwa WE, Subramaniam G, Mansor MB, Yan OS, Anbazhagan D, Devi SS. Iron regulated outer membrane proteins (IROMPs) as potential targets against carbapenemresistant Acinetobacter spp. isolated from a Medical Centre in Malaysia. Indian J Med Res. 2010; 131:578-83.

29. Hu FP, Guo Y, Zhu DM, Wang F, Jiang XF, Xu YC, Zhang XJ, Zhang CX, Ji P, Xie Y, Kang M, Wang CQ, Wang AM, et al. Resistance trends among clinical isolates in China reported from CHINET surveillance of bacterial resistance, 2005-2014. Clin Microbiol Infect. 2016; 22:S9-14. https:// doi.org/10.1016/j.cmi.2016.01.001.

30. Direkel S, Copur Cicek A, Karagoz A, Aydogan Ejder N, Oktay E, Delialioglu N, Ozgumus OB, Durmaz R. [Antimicrobial susceptibility and molecular characterization of multidrug-resistant Acinetobacter baumannii isolated in an university hospital]. [Article in Turkish]. Mikrobiyol Bul. 2016; 50:522-34.

31. Eghbalimoghadam M, Farahani A, Akbar FN, Mohajeri P. Frequency of Class 1 Integron and Genetic Diversity of Acinetobacter baumannii Isolated from Medical Centers in Kermanshah. J Nat Sci Biol Med. 2017; 8:193-8. https://doi. org/10.4103/0976-9668.210007. 
32. Tuan Anh N, Nga TV, Tuan HM, Tuan NS, Y DM, Vinh Chau NV, Baker S, Duong HH. Molecular epidemiology and antimicrobial resistance phenotypes of Acinetobacter baumannii isolated from patients in three hospitals in southern Vietnam. J Med Microbiol. 2017; 66:46-53. https://doi.org/10.1099/jmm.0.000418.

33. Jia W, Li C, Zhang H, Li G, Liu X, Wei J. Prevalence of Genes of OXA-23 Carbapenemase and AdeABC Efflux Pump Associated with Multidrug Resistance of Acinetobacter baumannii Isolates in the ICU of a Comprehensive Hospital of Northwestern China. Int J Environ Res Public Health. 2015; 12:10079-92. https://doi. org/10.3390/ijerph120810079.

34. Wong D, Nielsen TB, Bonomo RA, Pantapalangkoor P, Luna B, Spellberg B. Clinical and Pathophysiological Overview of Acinetobacter Infections: a Century of Challenges. Clin Microbiol Rev. 2017; 30:409-47. https:// doi.org/10.1128/CMR.00058-16.

35. Infectious Diseases Society of America. White paper: recommendations on the conduct of superiority and organism-specific clinical trials of antibacterial agents for the treatment of infections caused by drug-resistant bacterial pathogens. Colin Infect Dis. 2012; 55:1031-46. https://doi. org/10.1093/cid/cis688.

36. Eveillard M, Soltner C, Kempf M, Saint-Andre JP, Lemarie C, Randrianarivelo C, Seifert H, Wolff M, Joly-Guillou ML. The virulence variability of different Acinetobacter baumannii strains in experimental pneumonia. J Infect. 2010; 60:154-61. https://doi.org/10.1016/j.jinf.2009.09.004.

37. Sung JY, Koo SH, Kim S, Kwon GC. Persistence of Multidrug-Resistant Acinetobacter baumannii Isolates Harboring blaOXA-23 and bap for 5 Years. J Microbiol Biotechnol. 2016; 26:1481-9. https://doi.org/10.4014/ jmb.1604.04049.

38. Mohajeri P, Sharbati S, Farahani A, Rezaei Z. Evaluate the frequency distribution of nonadhesive virulence factors in carbapenemase-producing Acinetobacter baumannii isolated from clinical samples in Kermanshah. J Nat Sci Biol Med. 2016; 7:58-61. https://doi.org/10.4103/0976-9668.175071.

39. Loehfelm TW, Luke NR, Campagnari AA. Identification and characterization of an Acinetobacter baumannii biofilmassociated protein. J Bacteriol. 2008; 190:1036-44. https:// doi.org/10.1128/JB.01416-07.

40. Fallah A, Rezaee MA, Hasani A, Barhaghi MHS, Kafil HS. Frequency of bap and cpaA virulence genes in drug resistant clinical isolates of Acinetobacter baumannii and their role in biofilm formation. Iran J Basic Med Sci. 2017; 20:849-55. https://doi.org/10.22038/IJBMS.2017.9105.

41. Esmaeilkhani H, Rasooli I, Nazarian S, Sefid F. In vivo validation of the immunogenicity of recombinant Baumannii Acinetobactin Utilization A protein (rBauA). Microb Pathog. 2016; 98:77-81. https://doi.org/10.1016/j. micpath.2016.06.032.

42. Sefid F, Rasooli I, Jahangiri A. In silico determination and validation of baumannii acinetobactin utilization a structure and ligand binding site. Biomed Res Int. 2013; 2013:172784. https://doi.org/10.1155/2013/172784.

43. Luo TL, Rickard AH, Srinivasan U, Kaye KS, Foxman B. Association of blaOXA-23 and bap with the persistence of Acinetobacter baumannii within a major healthcare system. Front Microbiol. 2015; 6:182. https://doi.org/10.3389/ fmicb.2015.00182.

44. Grishin AM, Ajamian E, Tao L, Bostina M, Zhang L, Trempe JF, Menard R, Rouiller I, Cygler M. Family of phenylacetyl-CoA monooxygenases differs in subunit organization from other monooxygenases. J Struct Biol. 2013; 184:147-54. https://doi.org/10.1016/j. jsb.2013.09.012.

45. Clark RB. Imipenem resistance among Acinetobacter baumannii: association with reduced expression of a 33-36 $\mathrm{kDa}$ outer membrane protein. Journal of Antimicrobial Chemotherapy. 1996; 38:245-51.

46. Costa SF, Woodcock J, Gill M, Wise R, Barone AA, Caiaffa H, Levin AS. Outer-membrane proteins pattern and detection of beta-lactamases in clinical isolates of imipenem-resistant Acinetobacter baumannii from Brazil. Int J Antimicrob Agents. 2000; 13:175-82.

47. del Mar Tomas M, Beceiro A, Perez A, Velasco D, Moure R, Villanueva R, Martinez-Beltran J, Bou G. Cloning and functional analysis of the gene encoding the 33- to 36-kilodalton outer membrane protein associated with carbapenem resistance in Acinetobacter baumannii. Antimicrob Agents Chemother. 2005; 49:5172-5. https:// doi.org/10.1128/aac.49.12.5172-5175.2005.

48. Braun G, Vidotto MC. Evaluation of adherence, hemagglutination, and presence of genes codifying for virulence factors of Acinetobacter baumannii causing urinary tract infection. Mem Inst Oswaldo Cruz. 2004; 99:839-44. https://doi.org//S0074-02762004000800010.

49. Seifert H, Dolzani L, Bressan R, van der Reijden T, van Strijen B, Stefanik D, Heersma H, Dijkshoorn L. Standardization and interlaboratory reproducibility assessment of pulsed-field gel electrophoresis-generated fingerprints of Acinetobacter baumannii. J Clin Microbiol. 2005; 43:4328-35. https://doi.org/10.1128/ JCM.43.9.4328-4335.2005.

50. Dhanoa A, Rajasekaram G, Lean SS, Cheong YM, Thong KL. Endemicity of Acinetobacter calcoaceticus-baumannii complex in an intensive care unit in Malaysia. J Pathog. 2015; 2015:789265. https://doi.org/10.1155/2015/789265.

51. Van BA, Tassios PT, Dijkshoorn L, Haeggman S, Cookson B, Fry NK, Fussing V, Green J, Feil E, Gerner-Smidt P. Guidelines for the validation and application of typing methods for use in bacterial epidemiology. Clinical Microbiology \& Infection. 2007; 13:1-46.

52. CLSI. Performance Standards for Antimicrobial Susceptibility Testing. 27th ed. CLSI supplement M100. Wayne, PA: Clinical and Laboratory Standards Institute; 2017. 2017. 
53. Cucunawangsih, Wiwing V, Lugito NPH. Multidrug resistant Acinetobacter. Open Journal of Medical Microbiology. 2015; 05:85-9.

54. Badmasti F, Siadat SD, Bouzari S, Ajdary S, Shahcheraghi F. Molecular detection of genes related to biofilm formation in multidrug-resistant Acinetobacter baumannii isolated from clinical settings. Journal of Medical Microbiology. 2015; 64:559-64.

55. Gaddy JA, Arivett BA, Mcconnell MJ, Lópezrojas R, Pachón J, Actis LA. Role of Acinetobactin-Mediated Iron Acquisition Functions in the Interaction of Acinetobacter baumannii Strain ATCC 19606T with Human Lung Epithelial Cells, Galleria mellonella Caterpillars, and Mice. Infection \& Immunity. 2012; 80:1015.

56. Fiester SE, Arivett BA. Iron-Regulated Phospholipase C Activity Contributes to the Cytolytic Activity and Virulence of Acinetobacter baumannii. PLoS One. 2016; 11:e0167068. https://doi.org/10.1371/journal.pone.0167068.

57. Jacobs AC, Hood I, Boyd KL, Olson PD, Morrison JM, Carson S, Sayood K, Iwen PC, Skaar EP, Dunman PM. Inactivation of phospholipase $\mathrm{D}$ diminishes Acinetobacter baumannii pathogenesis. Infection \& Immunity. 2010; 78:1952.

58. Stahl J, Bergmann H, Göttig S, Ebersberger I, Averhoff B. Acinetobacter baumannii Virulence Is Mediated by the Concerted Action of Three Phospholipases D. Plos One. 2015; 10:e138360.

59. Smani Y, Dominguez-Herrera J, Pachon J. Association of the outer membrane protein Omp33 with fitness and virulence of Acinetobacter baumannii. J Infect Dis. 2013; 208:1561-70. https://doi.org/10.1093/infdis/jit386.

60. Rumbo C, Tomas M, Fernandez Moreira E, Soares NC, Carvajal M, Santillana E, Beceiro A, Romero A, Bou G. The
Acinetobacter baumannii Omp33-36 porin is a virulence factor that induces apoptosis and modulates autophagy in human cells. Infect Immun. 2014; 82:4666-80. https://doi. org/10.1128/iai.02034-14.

61. Choi CH, Lee EY, Lee YC, Park TI, Kim HJ, Hyun $\mathrm{SH}$, Kim SA, Lee SK, Lee JC. Outer membrane protein 38 of Acinetobacter baumannii localizes to the mitochondria and induces apoptosis of epithelial cells. Cell Microbiol. 2005; 7:1127-38. https://doi. org/10.1111/j.1462-5822.2005.00538.x.

62. Cerqueira GM, Kostoulias X, Chen K, Aibinu I, Qu Y, Traven A, Peleg AY. A Global Virulence Regulator in Acinetobacter baumannii and Its Control of the Phenylacetic Acid Catabolic Pathway. Journal of Infectious Diseases. 2014; 210:46. https://doi.org/10.1093/infdis/jiu024.

63. Bhuiyan MS, Ellett F, Murray GL, Kostoulias X, Cerqueira GM, Schulze KE, Mahamad Maifiah MH, Li J, Creek DJ, Lieschke GJ, Peleg AY. Acinetobacter baumannii phenylacetic acid metabolism influences infection outcome through a direct effect on neutrophil chemotaxis. Proc Natl Acad Sci U S A. 2016; 113:9599-604. https://doi. org/10.1073/pnas.1523116113.

64. Nothaft H, Szymanski CM. Protein glycosylation in bacteria: sweeter than ever. Nat Rev Microbiol. 2010; 8:765-78. https://doi.org/10.1038/nrmicro2383.

65. Li YF, Su N, Chen SY, Hu WX, Li FF, Jiang ZP, Yu XQ. Genetic background of Escherichia coli isolates from peritoneal dialysis patients with peritonitis and uninfected control subjects. Genet Mol Res. 2016; 15. https://doi. org/10.4238/gmr.15017341. 